\title{
Skin microcirculatory changes reflect early the circulatory deterioration in a fulminant sepsis model in the pig ${ }^{1}$
}

\author{
Ferenc Kiss ${ }^{\mathrm{I}}$, Levente MolnarI, Endre Hajdu ${ }^{\mathrm{II}}$, Adam Deak ${ }^{\mathrm{III}}$, Abel Molnar ${ }^{\mathrm{IV}}$, Marianna Berhes ${ }^{\mathrm{V}}$, Judit Szabo ${ }^{\mathrm{VI}}$, Norbert \\ Nemeth $^{\text {VII }}$, Bela Fulesdi ${ }^{\text {III }}$
}

DOI: http://dx.doi.org/10.1590/S0102-865020150070000004

IPhD, Assistant Lecturer, Department of Operative Techniques and Surgical Research, Institute of Surgery, Faculty of Medicine, University of Debrecen, Hungary. Technical procedures, acquisition and interpretation of data, statistics analysis, manuscript preparation and writing.

IIFellow PhD degree, Department of Anesthesiology and Intensive Therapy, Faculty of Medicine, University of Debrecen, Hungary. Assisted performing examinations, acquisition of data.

IIIDVM, PhD, Assistant Lecturer, Department of Operative Techniques and Surgical Research, Institute of Surgery, Faculty of Medicine, University of Debrecen, Hungary. Secured anesthesia assisted performing examinations.

${ }^{\text {IV }}$ MS, Faculty of Medicine, University of Debrecen, Hungary. Assisted and performed examinations.

${ }^{v}$ MD, Specialist, Department of Anesthesiology and Intensive Therapy, Faculty of Medicine, University of Debrecen, Hungary. Performed examinations. ${ }^{v} \mathrm{PhD}$, Associate Professor, Institute of Medical Microbiology, Faculty of Medicine, University of Debrecen, Hungary. Conception and design of the study.

${ }^{\mathrm{VII}} \mathrm{PhD}$, Associate Professor, Head, Department of Operative Techniques and Surgical Research, Institute of Surgery, Faculty of Medicine, University of Debrecen, Hungary. Technical procedures, intellectual and scientific content of the study, conception and design of the study, critical revision, final approval of the manuscript.

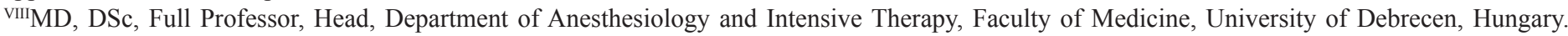
Intellectual and scientific content of the study, conception and design of the study, critical revision, final approval of the manuscript.

\section{ABSTRACT}

PURPOSE: In the pathophysiology of sepsis tissue perfusion dysfunction is a crucial driving force. Thus the early recognition is highly important. Concerning the early hours of bacteremia, and the systemic inflammatory response reaction leading to sepsis we aimed to investigate the micro- and macrocirculatory changes.

METHODS: In 20 juvenile Hungahib pigs were anesthetized and the femoral artery and external jugular vein were prepared unilaterally and cannulated. For assisted ventilation tracheostomy was performed. In Sepsis group ( $\mathrm{n}=11)$ live E. coli was intravenously administered (increasing concentration, $9.5 \times 10^{\wedge} 6$ in $3 \mathrm{~h}$ ). In Control group ( $\mathrm{n}=9$ ) bacteria-free saline was administered at the same volume. Modified shock index (MSI), core and skin temperature, and skin microcirculation (laser Doppler) were measured before inducing bacteremia then hourly for $4 \mathrm{~h}$.

RESULTS: In Control group parameters were stable, while six animals in the Sepsis group died before the $4^{\text {th }}$ hour. Core and skin temperature did not show significant alterations. In Sepsis group microcirculation showed a large impairment already by the 1st hour, while in MSI only by the 3rd hour.

CONCLUSION: During bacteremia and the early phase of sepsis microcirculatory impairment can be detected soon, even hours before the deterioration in hemodynamic parameters in this porcine model.

Key words: Bacteremia. Sepsis. Microcirculation. Hemodynamics. Shock. Models, Animal. Swine. 


\section{Introduction}

Still nowadays, the treatment of sepsis means a great challenge in clinical practice. Approximately more than 13 million people are treated with sepsis every year, the mortality rate of septic shock is over $50 \%{ }^{1-4}$, and it is the leading cause of death in the intensive care unit ${ }^{5,6}$.

It has been revealed that the microcirculatory impairment has significant importance in the septic process. As Ince described it, microcirculation is the motor of the sepsis ${ }^{7}$. Several studies enforced that there is a connection between the severity of microcirculatory disturbance and the development of organ dysfunction in sepsis ${ }^{8-11}$. And it is highlighted that especially in late states of the process, despite of adequate hemodynamic support to increase blood pressure and cardiac output, tissue perfusion remains impaired and the improvement in the outcome is failed, as well ${ }^{12-14}$.

Therefore sepsis is an active field of research and numerous experimental models have been established to investigate its complex pathomechanism ${ }^{15-17}$. Through the years several methods were developed and adopted into sepsis research to evaluate and properly quantify the changes occurring in the microcirculation ${ }^{18-21}$. Several parameters were proposed to evaluate microcirculation and some of them seem to be promising. However, there is not enough evidence about which is the most relevant, and what are the cut-off values that would correlate to the severity or what is the clinical relevance of individual microcirculatory abnormalities ${ }^{22}$. Besides these there are still unanswered questions and little is known about the early, initial bacteremic and systemic inflammatory response reaction phase of the septic process.

Our aim was to investigate the microcirculatory, hemodynamic and temperature changes in the early phase of the septic process in a fulminant sepsis model on anesthetized pigs.

\section{Methods}

\section{Experimental animals and operative techniques}

The experiments were approved and registered by the University of Debrecen Committee of Animal Welfare (permission Nr.: 21/2013. UD CAW), in accordance with the Hungarian Animal Protection Act (Law XVIII/1998 and the Edict 63/2010) and EU directives.

Twenty healthy female Hungahib pigs $(18.62 \pm 1.91$ $\mathrm{kg} ; 10-12$ weeks old) were involved into the experiment that was carried out under continuous general anesthesia $(15 \mathrm{mg} / \mathrm{kg}$ ketamine, i.m. $+1 \mathrm{mg} / \mathrm{kg}$ xylazine i.m.).

Both in Sepsis $(n=11)$ and Control $(n=9)$ groups inferior tracheostomy was performed for assisted ventilation, then the left external jugular vein and the left femoral artery were gently prepared, exposed and cannulated directly for invasive hemodynamic measurements. Blood sampling also occurred from the cannulae for widespread laboratory investigations (data not discussed in this paper). Besides physiological saline infusion (Salsol, Teva Pharmaceuticals Co., Ltd.; $125 \mathrm{ml} /$ hour i.v.), the animals did not receive anticoagulant or any medication during the experiment. The temperature of the operating room was set to approximately $25^{\circ} \mathrm{C}$ and a $37^{\circ} \mathrm{C}$-heating pad was placed under the animals.

In Sepsis group live Escherichia coli culture (2.5 x 105/ $\mathrm{ml}$, ATCC 25922 strain in physiological saline, Institute of Medical Microbiology, Faculty of Medicine, University of Debrecen) was intravenously administered in the following protocol: $2 \mathrm{ml}$ in $8 \mathrm{ml}$ physiological saline in 30 minutes, then $4 \mathrm{ml}$ in $6 \mathrm{ml}$ physiological saline in 30 minutes and $32 \mathrm{ml}$ in 2 hours (all together $9.5 \times 10^{6} \mathrm{E}$. coli, $52 \mathrm{ml}$ physiological saline in 3 hours).

In Control group the same amount of sterile physiological saline was administered by the same protocol as in the Sepsis group.

Microcirculatory, hemodynamic and temperature measurements were performed after surgery just before inducing bacteremia (base) then 1, 2, 3 and 4 hours later.

At the end of the experiment animals were euthanized.

\section{Temperature measurements}

The core temperature was measured via the venous cannula being at a central position by PiCCo Monitoring Kit (Pulsion Medical Systems SE, Germany) connected to Philips IntelliVue monitor (Koninklijke Philips N.V., The Netherlands). Skin temperature was measured on the medial surface of the right thigh by a SEN-06-RTH1 stick temperature probe (Experimetria Ltd., Hungary).

\section{Hemodynamic measurements}

Heart rate (HR [1/min]) and mean arterial pressure (MAP $[\mathrm{mmHg}])$ was monitored invasively by the PiCCO device. As a descriptive parameter for the circulation status the modified shock index (MSI [1/mmHg.min]) was calculated as the ratio of HR and MAP values ${ }^{23}$. 


\section{Microcirculatory measurements}

Microcirculation was monitored on the medial surface of the right thigh - near to the site, where skin temperature was measured - by a laser Doppler (LD) tissue flowmetry (LD-01, Experimetria Ltd., Hungary) using a miniature surface sensor (MSP300XP, Oxford Optronix Ltd., UK). Measurements were carried out on the same spot during the experimental protocol by gentle pressure-free tape-fixation of the sensor on the skin. The device is based on the laser Doppler method and it measures blood flux unit (BFU [AU]) that is determined by the number of moving red blood cells and their mean velocity in the measured volume ${ }^{24-26}$. After the detected signal became stable, data was recorded by S.P.E.L. Advanced Kymograph software (Experimetria Ltd., Hungary) at $1 \mathrm{kHz}$ sampling rate for 30 60 seconds. During off-line data analysis the average value of a noise-free 10-second long representative section of each recorded graph was calculated.

\section{Statistical analysis}

Data are presented as means \pm standard deviation (S.D.). For describing the magnitude of changes percentage values were calculated individually. For intra-group comparison one-way ANOVA with Bonferroni or Dunn's post hoc test was used. For inter-group comparison two-sample Student's t test or Wilcoxon Rank Sum test was performed depending on data distribution and equality of variances. Level of significance was set as $p<0.05$.

\section{Results}

\section{Survival time}

In the Control group all animals survived the experimental investigation time. In Sepsis group 6 out of the 11 animals passed away because of sudden circulatory failure during the 4-hour investigation period (Figure 1).

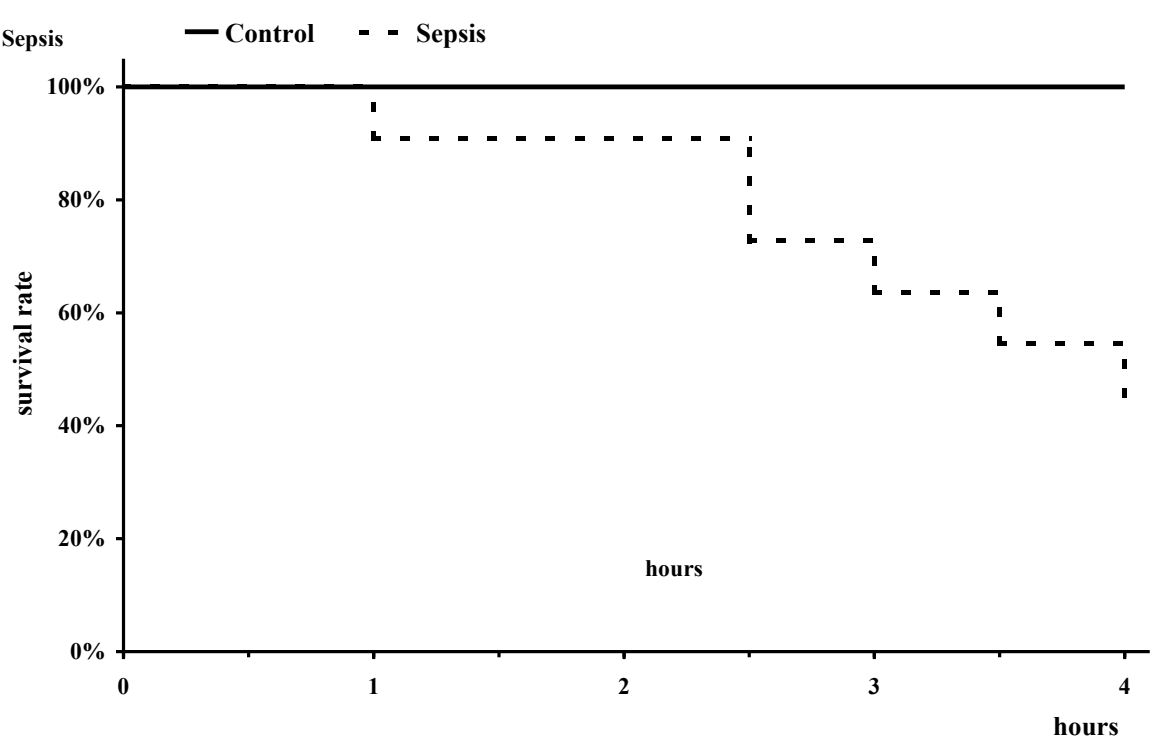

FIGURE 1 - Survival rate in the Control and Sepsis group during the 4-hour experimental investigation period.

\section{Core and skin temperature}

Table 1 shows the recorded temperature data in both experimental groups. Core temperature measured at a central venous location showed slight elevation $\left(1^{\circ} \mathrm{C}\right)$ by the $4^{\text {th }}$ hour in the Control group. In Sepsis group it increased by $1.3^{\circ} \mathrm{C}$ at the $1^{\text {st }}$ hour then slowly altogether by $1.7^{\circ} \mathrm{C}$ by the end of the investigation period compared to the base value.
Temperature measured on the medial surface of the right thigh showed an initial $2.3^{\circ} \mathrm{C}$ increase in the Control group that further only increased by $0.3 \%$. In Sepsis group skin surface temperature elevated by $1.3^{\circ} \mathrm{C}$ at the $1^{\text {st }}$ hour then dropped back close to its base value by the $3^{\text {rd }}$ hour and an altogether $1.8^{\circ} \mathrm{C}$ increase was detected by the end of the investigation period. Significant inter- or intra-group difference was not found. 


\section{Hemodynamic parameters}

Table 1 shows the calculated modified shock index (MSI) as a descriptive parameter of the hemodynamic status. It increased by $10.3 \pm 22.3 \%$ in the Control group by the end of the investigation time. In Sepsis group MSI showed similar pattern to Control group until the $3^{\text {rd }}$ hour then it markedly increased by $40.7 \pm 49.9 \%$ compared to its base values and remained elevated by $34.9 \pm 45.9 \%$ to its base value. Significant inter- or intra-group difference was not found.

TABLE 1 - Changes of core- and skin surface temperature and modified shock index values in the Control and Sepsis groups.

\begin{tabular}{ccccccc}
\hline Variable & Group & Base & 1 hour & 2 hours & 3 hours & 4 hours \\
\hline core temperature $\left[{ }^{\mathbf{C}} \mathbf{C}\right]$ & Control & $36.34 \pm 0.5$ & $36.49 \pm 0.63$ & $36.87 \pm 0.84$ & $37.13 \pm 0.77$ & $37.33 \pm 0.76$ \\
& Sepsis & $35.92 \pm 2.78$ & $37.19 \pm 0.85$ & $37.23 \pm 0.81$ & $37.52 \pm 0.78$ & $37.56 \pm 0.93$ \\
skin surface & Control & $30.76 \pm 1.41$ & $33.08 \pm 1.48$ & $33.58 \pm 1.91$ & $32.98 \pm 1.2$ & $33.15 \pm 1.6$ \\
temperature $\left[{ }^{\circ} \mathbf{C}\right]$ & Sepsis & $31.69 \pm 2$ & $33.05 \pm 1.62$ & $32.81 \pm 1.55$ & $32.14 \pm 1.83$ & $33.46 \pm 0.47$ \\
modified shock index & Control & $0.85 \pm 0.22$ & $0.9 \pm 0.25$ & $0.91 \pm 0.28$ & $0.91 \pm 0.21$ & $0.91 \pm 0.15$ \\
(MSI) [1/mmHg.min] & Sepsis & $0.93 \pm 0.18$ & $0.96 \pm 0.25$ & $0.92 \pm 0.33$ & $1.22 \pm 0.46$ & $1.11 \pm 0.22$ \\
\hline
\end{tabular}

means \pm S.D.

\section{Microcirculatory parameters}

Figure 2 shows the microcirculatory tissue perfusion describing blood flux unit (BFU) changes in the two groups during the investigated time. In Control group BFU dropped by $15.3 \%$ at the $1^{\text {st }}$ hour (from $65.4 \pm 17.41$ to $55.38 \pm 23.48$ ) but it returned to around the its base value and were stable later on $(64.44 \pm 25.79$, $66.73 \pm 20.5$ and $63.04 \pm 15.74$, respectively). In Sepsis group a significant $41.2 \pm 23.1 \%$ drop was detected by the $1^{\text {st }}$ hour (from $63.68 \pm 18.23$ to $36.03 \pm 9.42 ; p=0.024)$. Microcirculatory tissue perfusion values remained low during the investigation period, however after the $40 \%$ drop it slightly increased by the $2^{\text {nd }}$ hour then started to drop again $(40.9 \pm 28.68,34.67 \pm 23.82$ and $23.12 \pm$ $7.33)$. By the $4^{\text {th }}$ hour the decrease was again significant compared to the base values $(p=0.008)$. The noticed decrease in the BFU values in the Sepsis group was obvious compared to the Control group. The difference between the BFU values of the two groups did not reach the significance level at the $1^{\text {st }}$ and $3^{\text {rd }}$ hours $(p=0.065$ and $p=0.052$, respectively), but became significant by the $4^{\text {th }}$ hour $(\mathrm{p}=0.006)$.

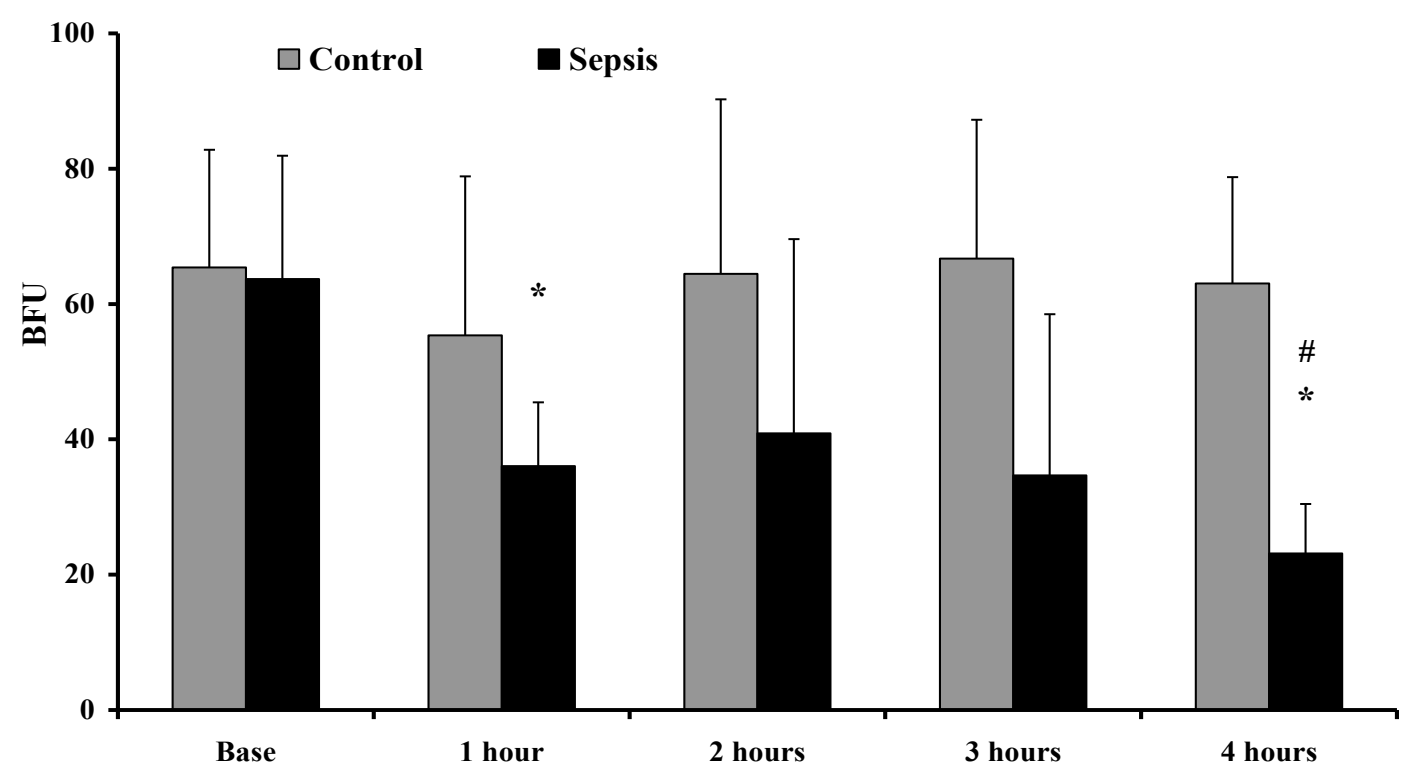

FIGURE 2 - Microcirculatory perfusion describing blood flux unit (BFU) values on the skin in the Control and Sepsis groups.

Means \pm S.D., ${ }^{*} \mathrm{p}<0.05$ vs. base; \# $\mathrm{p}<0.05$ vs. Control 
For evaluating the changes in the skin BFU and in the ratio of core/skin temperature as one parameter, we calculated their ratio. On Figure 3 it is shown that the core/skin temperature changes did not correlate with the skin microcirculatory impairment in the Sepsis group. However, the calculation of their ratios caused statistical difference at more measured time- points than the comparison of BFU values only. In the Sepsis group all values were statistically lower compared to its base value $(\mathrm{p}=0.041, \mathrm{p}=0.017, \mathrm{p}=0.016, \mathrm{p}=0.006$, respectively). Sepsis group showed significantly lower values at the $2^{\text {nd }}, 3^{\text {rd }}$ and $4^{\text {th }}$ hour versus the Control group $(p=0.043, p=0.016, p=0.002$, respectively).

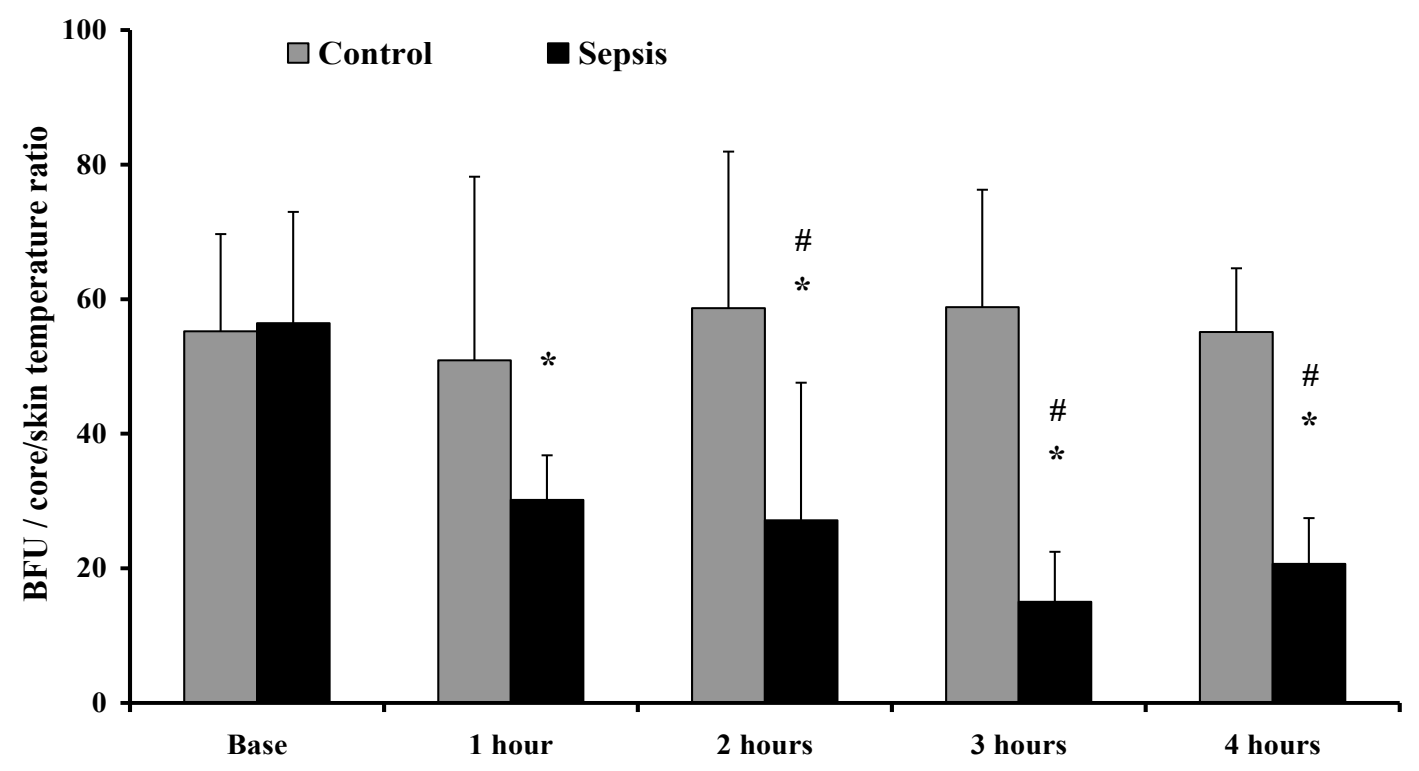

FIGURE 3 - The ratio of skin microcirculatory perfusion describing blood flux unit (BFU) and core/skin temperature values in the Control and Sepsis groups.

Means \pm S.D., ${ }^{*} \mathrm{p}<0.05$ vs. base; \# $\mathrm{p}<0.05$ vs. Control

\section{Discussion}

Through the years several experimental animal models have been developed to investigate sepsis ${ }^{15-17}$. Unfortunately all of them have limitations about modeling sepsis. In clinical practice septic patients are many times neonates, infants or elderly patients with various multiple co-morbidities, and in most cases sepsis is caused not only by one well-defined strain of organism. Under experimental conditions the laboratory/experimental animals are usually young and healthy ones. Sepsis is induced either by one strain of organism in a defined way with a settle dose (e.g. intravascular administration of bacteria) to provide standardized conditions for the experiment or by focusing more on natural ways (e.g. cecum ligation and puncture) but losing on the side of standardized and well-controlled induction of the septic process ${ }^{15,17,27}$. During any experimental research it is crucial to use a reliable, standardized experimental model that will representative, comparable and extrapolable data in order to respect animal rights and follow the principles of the $3 \mathrm{R}^{\prime} \mathrm{s}^{28}$.
Among the possible models described in the literature we induced bacteremia and sepsis process in young 10-12 weeks old pigs by intravenous administration of live Escherichia coli in an increasing dose. By our knowledge there are only a few studies available that investigated the septic process on big-experimental animal model focusing on microcirculatory, hemodynamic and temperature changes, but most of them focused on events hours after bacteremia was intravenously induced and not completely from the initial period.

In our experimental set-up the nine control animals had stable parameters during the 4-hour investigation period, while in the Sepsis group 6 out of the 11 animals died, from what five even before the complete dose of the Escherichia coli could have been administered. Analyzing the Sepsis group by comparing the data of the animals that died before the end of the investigation period to the ones that survived for 4 hours, we found that laser Doppler tissue microcirculation values did not show major differences between them, in all animals it was largely impaired. In 3 out of the 6 non-survivals the modified shock index showed great elevation 
approximately 30-60 minutes prior to death (MSI: 21.2\%, 57.1\%, $21.7 \%$, respectively), which was mostly due to the elevation in the heart rate (HR: $12.1 \%, 42.1 \%, 23.5 \%$, respectively). Besides these the other presented parameters did not show any predictable signs for the upcoming death in the retrospective analysis.

Sepsis group animals that survived the 4-hour investigation period had similar heart rate and modified shock index changes by the $3^{\text {rd }}$ and mostly by the $4^{\text {th }}$ hour to the non-survivals, while mean arterial pressure did not show much of alteration. Skin and core temperature minimally elevated in both Control and Sepsis groups during the investigation period. Laser Doppler-determined blood flux unit measured on the skin was stable in the Control group but in the Sepsis group it showed a significant drop already by the $1^{\text {st }}$ hour after prompting the bacteremia and it was even larger by the $4^{\text {th }}$ hour. Neither core, nor skin temperature changes correlated with the experienced impairment of skin microcirculation in the Sepsis group in this investigated initial phase of the septic process. However, it also has to be taken under consideration that the length of the investigation time was relatively short, due to the anesthesia thermoregulation was affected and a $37^{\circ} \mathrm{C}$-heating pad was placed under the animals to support maintaining their body temperature.

Boerma et al..$^{29}$ compared microcirculatory changes to central-to-toe temperature difference changes in patients with severe sepsis or septic shock during the first 6 hours of intensive care unit admission. They concluded that the impairment in the microcirculatory parameters determined by orthogonal polarization spectral (OPS) imaging technique showed no correlation with the central-to-toe temperature changes.

On the other side Papaioannou et al. ${ }^{30}$ highlighted the importance of skin temperature measurements and the calculation of reduced wavelet Shannon and Tsallis entropies from temperature data of septic patients during the first 24 hours because they found significant difference between the data of survivals and nonsurvivals.

Wester et $a l .^{31}$ investigated the changes of skin and sublingual microcirculatory changes in intravenous administration of heat-inactivated Neisseria meningitidis sepsis model on pigs. 200 minutes after sepsis was induced microcirculatory measurements were performed by laser Doppler and computer assisted video microscopy and they concluded that the degree of skin and sublingual microcirculatory impairment can be related to the severity of the sepsis.

In our experiment we performed microcirculatory measurements also on the sublingual area and on the tongue using a standard pencil probe (MNP100XP, Oxford Optronix Ltd., UK), but the recorded data were not evaluable. It was probably due to the continuous drying of the mucosal surface, although the tongue was covered with wet textile during the experiment.

Verdant et al..$^{32}$ investigated and compared sublingual and intestinal mucosa microcirculatory changes also in a porcine model, where cholangitis was induced by E. coli infusion into the common bile duct. Microcirculatory parameters were measured by OPS imaging technique. The first measurement were carried out 4 hours after E. coli was administered and they found significant decrease of the microcirculatory perfusion flow in both regions and its evolution was similar in severity and in timing.

Boerma et $a l .^{33}$ also used OPS imaging technique to compare the microcirculatory changes of sublingual and intestinal mucosa. They investigated septic patients with newly constructed intestinal stoma, and concluded that the microcirculatory parameters measured on the two different tissues did not show any correlation on the $1^{\text {st }}$ postoperative day. However, on the $3^{\text {rd }}$ postoperative day positive correlation was found but they mentioned that by that time both microcirculatory and macrocirculatory flow parameters normalized.

The actual state of microcirculation shows large diversity inside of an exact organ and among the organs. It is based on the actual oxygen demand of different cells and on the actual function and importance of the organ ${ }^{34}$. Therefore it is not surprising that there are controversial data in the literature about how the microcirculatory state of various tissues can correlate with each other and how they can characterize the microcirculatory state of the whole body. However, performing microcirculatory measurements at different sampling sites and at a higher number a more accurate and proper description can be provided about the microcirculatory state, which can have a predictive, signaling value hours before macrocirculatory or other parameters shift markedly.

\section{Conclusions}

Skin microcirculatory and tissue perfusion distortion develops in the bacteremia and the early phase of bacteremia and sepsis, while hemodynamic parameters start to change hours later of it. The magnitude of changes in skin microcirculatory blood flow shows no correlation with skin and core temperature during the first 4 hours following bacteremia.

\section{References}

1. Angus DC, Pereira CA, Silva E. Epidemiology of severe sepsis around the world. Endocr Metab Immune Disord Drug Targets. 2006 Jun;6(2):207-12. PMID: 16787296. 
2. Levy MM, Fink MP, Marshall JC, Abraham E, Angus D, Cook D, Cohen J, Opal SM, Vincent JL, Ramsay G, Sccm/Esicm/Accp/ Ats/Sis. $2001 \mathrm{SCCM} / \mathrm{ESICM} / \mathrm{ACCP} / \mathrm{ATS} /$ SIS International Sepsis Definitions Conference. Crit Care Med. 2003 Apr;31(4):1250-6. PMID: 12682500.

3. Remick DG. Pathophysiology of sepsis. Am J Pathol. 2007 May;170(5):1435-44. PMID: 17456750.

4. Sagy M, Al-Qaqaa Y, Kim P. Definitions and pathophysiology of sepsis. Curr Probl Pediatr Adolesc Health Care. 2013 NovDec;43(10):260-3. PMID: 24295606.

5. Alberti C, Brun-Buisson C, Burchardi H, Martin C, Goodman S, Artigas A, Sicignano A, Palazzo M, Moreno R, Boulme R, Lepage E, Le Gall R. Epidemiology of sepsis and infection in ICU patients from an international multicentre cohort study. Intensive Care Med. 2002 Feb;28(2):108-21. PMID: 11907653.

6. Sharawy N, Lehmann C. New directions for sepsis and septic shock research. J Surg Res. 2015 Apr;194(2):520-7. PMID: 25596653.

7. Ince C. The microcirculation is the motor of sepsis. Crit Care. 2005 Aug;9 Suppl 4:S13-9. PMID: 16168069.

8. De Backer D, Donadello K, Cortes DO. Monitoring the microcirculation. J Clin Monit Comput. 2012 Oct;26(5):361-6. PMID: 22833180.

9. De Backer D, Donadello K, Sakr Y, Ospina-Tascon G, Salgado D, Scolletta S, Vincent JL. Microcirculatory alterations in patients with severe sepsis: impact of time of assessment and relationship with outcome. Crit Care Med. 2013 Mar;41(3):791-9. PMID: 23318492.

10. Sakr Y, Dubois MJ, De Backer D, Creteur J, Vincent JL. Persistent microcirculatory alterations are associated with organ failure and death in patients with septic shock. Crit Care Med. 2004 Sep;32(9):1825-31. PMID: 15343008.

11. Doerschug KC, Delsing AS, Schmidt GA, Haynes WG. Impairments in microvascular reactivity are related to organ failure in human sepsis. Am J Physiol Heart Circ Physiol. 2007 Aug;293(2):H1065-71. PMID: 17483235.

12. Levy B, Collin S, Sennoun N, Ducrocq N, Kimmoun A, Asfar P, Perez P, Meziani F. Vascular hyporesponsiveness to vasopressors in septic shock: from bench to bedside. Intensive Care Med. 2010 Dec;36(12):2019-29. PMID: 20862451.

13. Asfar P, Meziani F, Hamel JF, Grelon F, Megarbane B, Anguel N, Mira JP, Dequin PF, Gergaud S, Weiss N, Legay F, Le Tulzo Y, Conrad M, Robert R, Gonzalez F, Guitton C, Tamion F, Tonnelier JM, Guezennec P, Van Der Linden T, Vieillard-Baron A, Mariotte E, Pradel G, Lesieur O, Ricard JD, Herve F, du Cheyron D, Guerin C, Mercat A, Teboul JL, Radermacher P, Investigators S. High versus low blood-pressure target in patients with septic shock. N Engl J Med. 2014 Apr;370(17):1583-93. PMID: 24635770.

14. Ospina-Tascon G, Neves AP, Occhipinti G, Donadello K, Buchele G, Simion D, Chierego ML, Silva TO, Fonseca A, Vincent JL, De Backer D. Effects of fluids on microvascular perfusion in patients with severe sepsis. Intensive Care Med. 2010 Jun;36(6):949-55. PMID: 20221744.

15. Esmon CT. Why do animal models (sometimes) fail to mimic human sepsis? Crit Care Med. 2004 May;32(5 Suppl):S219-22. PMID: 15118521.

16. Fink MP. Animal models of sepsis. Virulence. 2014 Jan;5(1):14353. PMID: 24022070.

17. Poli-de-Figueiredo LF, Garrido AG, Nakagawa N, Sannomiya P. Experimental models of sepsis and their clinical relevance. Shock. 2008 Oct;30 Suppl 1:53-9. PMID: 18704008.

18. Casserly B, Read R, Levy MM. Hemodynamic monitoring in sepsis. Crit Care Nurs Clin North Am. 2011 Mar;23(1):149-69. PMID: 21316573.

19. Christ F, Bauer A, Brugger D. Different optical methods for clinical monitoring of the microcirculation. Eur Surg Res. 2002 JanApr;34(1-2):145-51. PMID: 11867915.

20. De Backer D, Ospina-Tascon G, Salgado D, Favory R, Creteur J, Vincent JL. Monitoring the microcirculation in the critically ill patient: current methods and future approaches. Intensive Care Med. 2010 Nov;36(11):1813-25. PMID: 20689916.

21. Shapiro NI, Angus DC. A review of therapeutic attempts to recruit the microcirculation in patients with sepsis. Minerva Anestesiol. 2014 Feb;80(2):225-35. PMID: 24002463.

22. Hernandez G, Bruhn A, Ince C. Microcirculation in sepsis: new perspectives. Curr Vasc Pharmacol. 2013 Mar;11(2):161-9. PMID: 23506495.

23. Liu YC, Liu JH, Fang ZA, Shan GL, Xu J, Qi ZW, Zhu HD, Wang $\mathrm{Z}, \mathrm{Yu} \mathrm{XZ}$. Modified shock index and mortality rate of emergency patients. World J Emerg Med. 2012 Jun;3(2):114-7. PMID: 25215048.

24. Guy RH, Tur E, Maibach HI. Optical techniques for monitoring cutaneous microcirculation. Recent applications. Int J Dermatol. 1985 Mar;24(2):88-94. PMID: 3157651.

25. Nilsson GE, Tenland T, Oberg PA. Evaluation of a laser Doppler flowmeter for measurement of tissue blood flow. IEEE Trans Biomed Eng. 1980 Oct;27(10):597-604. PMID: 6449469.

26. Riva C, Ross B, Benedek GB. Laser Doppler measurements of blood flow in capillary tubes and retinal arteries. Invest Ophthalmol. 1972 Nov;11(11):936-44. PMID: 4634958.

27. Dyson A, Singer M. Animal models of sepsis: why does preclinical efficacy fail to translate to the clinical setting? Crit Care Med. 2009 Jan;37(1 Suppl):S30-7. PMID: 19104223.

28. Lilley E, Armstrong R, Clark N, Gray P, Hawkins P, Mason K, Lopez-Salesansky N, Stark AK, Jackson SK, Thiemermann C, Nandi M. Refinement of Animal Models of Sepsis and Septic Shock. Shock. 2015 Apr;43(4):304-16. PMID: 25565638.

29. Boerma EC, Kuiper MA, Kingma WP, Egbers PH, Gerritsen RT, Ince C. Disparity between skin perfusion and sublingual microcirculatory alterations in severe sepsis and septic shock: a prospective observational study. Intensive Care Med. 2008 Jul;34(7):1294-8. PMID: 18317733.

30. Papaioannou VE, Chouvarda IG, Maglaveras NK, Baltopoulos GI, Pneumatikos IA. Temperature multiscale entropy analysis: a promising marker for early prediction of mortality in septic patients. Physiol Meas. 2013 Nov;34(11):1449-66. PMID: 24149496.

31. Wester T, Haggblad E, Awan ZA, Barratt-Due A, Kvernebo M, Halvorsen PS, Mollnes TE, Kvernebo K. Assessments of skin and tongue microcirculation reveals major changes in porcine sepsis. Clin Physiol Funct Imaging. 2011 Mar;31(2):151-8. PMID: 21087397.

32. Verdant CL, De Backer D, Bruhn A, Clausi CM, Su F, Wang Z, Rodriguez H, Pries AR, Vincent JL. Evaluation of sublingual and gut mucosal microcirculation in sepsis: a quantitative analysis. Crit Care Med. 2009 Nov;37(11):2875-81. PMID: 19770750.

33. Boerma EC, van der Voort PH, Spronk PE, Ince C. Relationship between sublingual and intestinal microcirculatory perfusion in patients with abdominal sepsis. Crit Care Med. 2007 Apr;35(4):105560. PMID: 17334238 .

34. Klijn E, Den Uil CA, Bakker J, Ince C. The heterogeneity of the microcirculation in critical illness. Clin Chest Med. 2008 Dec;29(4):643-54. PMID: 18954699.

\section{Acknowledgement}

To the technical staff of the Department of Operative Techniques and Surgical Research. 


\section{Correspondence:}

Ferenc Kiss

Department of Operative Techniques and Surgical Research

Institute of Surgery, Faculty of Medicine

University of Debrecen

H-4032 Debrecen, Nagyerdei krt. 98

P.O.Box: 21 Hungary

Phone/Fax: 36-52-416-915

kife@med.unideb.hu

Received: March 8, 2015

Review: May 11, 2015

Accepted: June 10, 2015

Conflict of interest: none

Financial source: Hungarian Brain Research Program (Grant No. KTIA_13_NAP-A-II/5)

${ }^{1}$ Research performed at Department of Operative Techniques and Surgical Research, Institute of Surgery, Faculty of Medicine, University of Debrecen, Hungary. 